\title{
Correction to: Current Perspective on MDMA-Assisted Psychotherapy for Posttraumatic Stress Disorder
}

\author{
Sascha B. Thal ${ }^{1} \cdot$ Miriam J. J. Lommen ${ }^{1}$
}

Published online: 1 February 2018

(c) The Author(s) 2018. This article is an open access publication

\section{Correction to: Journal of Contempory Psychotherapy https://doi.org/10.1007/s10879-017-9379-2}

The original version of the article unfortunately contained a mistake in Abstract and in text under "What Does MDMA-Assisted Therapy Look Like?" section.

In abstract, the phrase "MDMD-assisted psychotherapy" has been changed to "MDMA-assisted psychotherapy" and the correct sentence should read as below:

"Empirical support for the use of MDMA-assisted psychotherapy, including the randomized, double-blind, placebo-controlled trails that have been conducted since 2008, is discussed."

In "What Does MDMA-Assisted Therapy Look Like?" section, the phrase "three 90-min sessions" was incorrectly published as "39-min sessions". The corrected sentence is given below:
The original article can be found online at https://doi.org/10.1007/ s10879-017-9379-2.

Miriam J. J. Lommen

m.j.j.lommen@rug.nl

1 Department of Clinical Psychology and Experimental Psychopathology, University of Groningen, Grote Kruisstraat 2/1, 9712 TS Groningen, The Netherlands
The sessions can be subdivided into three stages: A preparatory stage (usually consisting of three 90 -min sessions), followed by one substance-assisted session (including an overnight stay at the facility), succeeded by an integration stage (of several sessions). Systematic trauma exploration does not take place until the first substance-assisted session.

This has been corrected in the original version of the article.

Open Access This article is distributed under the terms of the Creative Commons Attribution 4.0 International License (http://creativecommons.org/licenses/by/4.0/), which permits unrestricted use, distribution, and reproduction in any medium, provided you give appropriate credit to the original author(s) and the source, provide a link to the Creative Commons license, and indicate if changes were made. 